\title{
NO 供体型马蹄金素衍生物的合成及其初步的抗乙肝病毒活性
}

\author{
梁光平 $a, b$ 曹佩雪 ${ }^{a}$ 杨秀虾 $a, b$ 黄正明 $c$ \\ 刘青川 ${ }^{c}$ 梁光义 ${ }^{*, a}$ 徐必学 $*, a$ \\ ( ${ }^{a}$ 贵州省中国科学院天然产物化学重点实验室 贵阳 550002) \\ ( ${ }^{b}$ 贵阳中医学院 贵阳 550002) \\ ( ${ }^{c}$ 中国人民解放军第三 $\bigcirc$ 二医院 北京 100039)
}

\begin{abstract}
摘要 以马蹄金素 $[N$-( $N$-苯甲酰基- $L$-苯丙氨酰基)- $O$-乙酰基 $-L$-苯丙氨醇, MTS $]$ 为先导化合物，设计并合成了 11 个 NO 供体型马蹄金素衍生物, 所有目标产物均未见文献报道, 其结构经 NMR, ESI-MS 确认. 以 HepG2 2.2.15 细胞为乙肝病 毒载体, 对合成的马蹄金素衍生物进行了抗乙肝病毒活性测试. 结果表明, 在测试浓度范围内, 化合物 $\mathbf{6 d}, \mathbf{6 e}, \mathbf{6 g}$ 具有 抗 $\mathrm{HBV}$ 活性, 其半数抑制浓度分别为 $6.88,37.51,11.07 \mu \mathrm{mol} / \mathrm{L}$. 其中, 化合物 $\mathbf{6 d}$ 和 $\mathbf{6 g}$ 的半数抑制浓度优于 MTS (11.16 $\mu \mathrm{mol} / \mathrm{L}$ ), 且具有较高的抑制率, 具有进一步研究开发的价值.
\end{abstract}

关键词 马蹄金素衍生物; 一氧化氮供体; 合成; 抗乙肝病毒活性

\section{Synthesis and Anti-hepatitis B Virus Activities of Nitric Oxide-Releasing Derivatives of Matijin-Su}

\author{
Liang, Guangping ${ }^{a, b} \quad$ Cao, Peixue $^{a} \quad$ Yang, Xiuxia $^{a, b} \quad$ Huang, Zhengming ${ }^{c}$ \\ Liu, Qingchuan ${ }^{c} \quad$ Liang, Guangyi* ${ }^{*, a} \quad$ Xu, Bixue ${ }^{*, a, b}$ \\ $\left({ }^{a}\right.$ Key Laboratory of Chemistry for Natural Products of Guizhou Province and \\ Chinese Academy of Sciences, Guiyang 550002) \\ $\left({ }^{b}\right.$ Guiyang College of Traditional Chinese Medicine, Guiyang 550002) \\ ( ${ }^{c} 302$ Hospital of PLA, Beijing 100039)
}

\begin{abstract}
By using $N$-( $N$-benzoyl- $L$-phenylalanyl)- $O$-acetyl- $L$-phenylalanol, named Matijin-Su, as a lead compound, a series of nitric oxide-releasing derivatives of Matijin-Su were synthesized and evaluated for their anti-hepatitis B virus activities in HepG2 2.2.15 cells. Compounds $\mathbf{6 d}, \mathbf{6 e}$ and $\mathbf{6 g}$ exhibited significant anti-HBV activities. The $50 \%$ inhibitory concentrations of these compounds towards HepG2 2.2.15 cells were 6.88, 37.51 and $11.07 \mu \mathrm{mol} / \mathrm{L}$. Compounds $\mathbf{6 d}$ and $\mathbf{6 g}$ were less than Matijin-Su $\left(\mathrm{IC}_{50}: 11.16 \mu \mathrm{mol} / \mathrm{L}\right)$. Compound $\mathbf{6 d}$ has potent in vitro anti-HBV activity, and could be worth of further research.

Keywords derivatives of Matijin-Su; nitric oxide donor; synthesis; anti-hepatitis B virus activity
\end{abstract}

乙肝是由乙肝病毒(hepatitis B virus, HBV)感染引 起的, 慢性乙肝是当前最严重的健康问题之一, 全球估 计有 20 亿人感染乙肝病毒, 3.5 亿以上的人群患有慢性 肝脏感染疾病, 其中约 $80 \%$ 分布在亚太地 ${ }^{[1]}$. 全球每 年约有 100 万人死于乙肝病毒感染的相关疾病, 占疾病 死因的第九位 ${ }^{[2,3]}$. 目前用于治疗乙肝的药物主要有以 拉米夫定为代表的核苷类药物 ${ }^{[4]}$ 和以干扰素 $-\alpha$ 为代表的
生物类免疫调节剂 ${ }^{[5]}$ ，但是这些药物都存在副作用大、 容易产生耐药、停药易发生“反跳”等缺陷 ${ }^{[6-8]}$. 因此, 寻 找和开发新的抗乙肝病毒药物具有重要的意义.

马蹄金素 $[N-(N$-苯甲酰基- $L$-苯丙氨酰基)- $O$-乙酰 基- $L$-苯丙氨醇, MTS]是梁光义教授研究组从旋花科植 物马蹄金(Dichondra repens Forst.)中分离得到单体化合 物, 具有较好的抗 HBV 活性(图 1), 其化学骨架与核苷

\footnotetext{
*E-mail: guangyi liang@126.com; bixue_xu@126.com

Received December 2, 2013; revised January 3, 2014; published online January 3, 2014.

Project supported by the National Natural Science Foundation of China (No. 81360472), and the Graduate Education Innovation Project of Guiyang College of Traditional Chinese Medicine (No. ZYYCX12018).

国家自然科学基金(No. 81360472)、贵阳中医学院研究生教育创新计划(No. ZYYCX12018)资助项目.
} 
类和干扰素等药物的化学骨架不同, 是一新化学骨架类 型的抗乙肝病毒化合物. 本研究组 ${ }^{[9 \sim 11]}$ 以马蹄金素为先 导化合物, 设计合成了部分衍生物, 并对其进行抗 HBV 活性测试, 发现了一些具有较好的抗乙肝病毒活性的化 合 物.

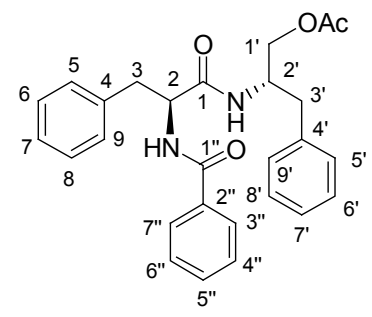

图 1 马蹄金素的化学结构式

Figure 1 Chemical structure of Matijin-Su

硝酸酯类化合物在医药方面主要体现在它是优良 的 NO 供体，由其产生的 NO 可使 DNA 碱基部分脱氨基

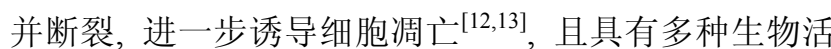
性，如细胞毒性、中枢肌松作用、扩张血管、降低血压 等作用, NO 还可以作用于病毒复制的早期阶段，从而 达到阻止病毒的扩散、促进病毒的清除和宿主的恢 复 ${ }^{[14 ~ 18]}$. 因此, NO 供体型化合物具有潜在的抗病毒活
性. 而马蹄金素具有较好的抗乙肝病毒活性，停药后未 见 “反跳” 现象，且结构中含有一个乙酸酯，可水解裸 露出醇羟基，将硝基与该羟基偶联，再于该化合物其他 取代位点引入不同的取代基，通过设计并合成一系列的 硝酸酯类 NO 供体型 MTS 衍生物，并对所合成的化合物 进行初步的体外抗 HBV 活性的篮选, 以期获得具有进 一步研究价值的活性化合物，同时也开拓硝酸酯类 $\mathrm{NO}$ 供体型化合物的应用范围。目标产物的合成路线见 Scheme 1

\section{1 结果与讨论}

\section{1 合成实验}

以 $L$-酪氨酸和苯甲酰氯为起始原料，合成 $N$-苯甲 酰基- $O$-苯甲酰基- $L$-酪氨酸(1)，再在 $N$-甲基吗啡啉 $(\mathrm{NMM})$ 、氯甲酸异丁酯(IBCF)的存在下发生缩合反应生 成 $N$-( $N$-苯甲酰基- $O$-苯甲酰基- $L$-酪氨酰基)- $L$-苯丙氨醇 (2), 化合物 2 与氢氧化钠在 $N, N$-二甲基甲酰胺的存在下 发生水解得 $N$-( $N$-苯甲酰基- $L$-酪氨酰基)- $L$-苯丙氨醇 $(3)$, 3 步反应产率为 $65.2 \%$. 再经发烟硝酸、醋酸、甲醇等 的作用下得到 $N$-( $N$-苯甲酰基- $O$-乙酰基- $L$-酪氨酰基)- $O$ -

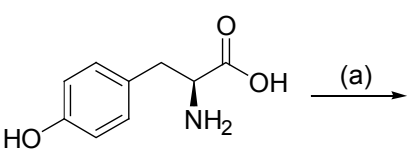<smiles>O=C(N[C@@H](Cc1ccc(OC(=O)c2ccccc2)cc1)C(=O)O)c1ccccc1</smiles>

1 (b)<smiles>O=C(NC(Cc1ccc(OC(=O)c2ccccc2)cc1)C(=O)N[C@@H](CO)Cc1ccccc1)c1ccccc1</smiles><smiles>O=C(N[C@@H](CO)Cc1ccccc1)C(=O)N[C@@H](CO)Cc1ccccc1</smiles>

3<smiles>[R]Oc1ccc(C[C@H](NC(=O)c2ccccc2)C(=O)N[C@H](CO[Na])Cc2ccccc2)cc1</smiles>

(d)<smiles>Cc1ccc(C(=O)N[C@@H](Cc2ccc(OC(C)(C)C)cc2)C(=O)N[C@@H](CO[N+](=O)[O-])Cc2ccccc2)cc1</smiles><smiles>CC(C)C</smiles>

$$
\begin{aligned}
& \text { 6a: } \mathrm{R}=\mathrm{CH}_{2} \mathrm{CH}_{2} \mathrm{~N}\left(\mathrm{CH}_{3}\right)_{2} \\
& \text { 6b: } \mathrm{R}=\mathrm{CH}_{2} \mathrm{CH}_{2} \mathrm{~N}\left(\mathrm{C}_{2} \mathrm{H}_{5}\right)_{2} \\
& \text { 6c: } \mathrm{R}=\left(\mathrm{CH}_{2}\right)_{3} \mathrm{CH}_{3} \\
& \text { 6d: } \mathrm{R}=\left(\mathrm{CH}_{2}\right)_{7} \mathrm{CH}_{3} \\
& \text { 6e: } \mathrm{R}=\left(\mathrm{CH}_{2}\right)_{4} \mathrm{CH}_{3} \\
& \text { 6f: } \mathrm{R}=\mathrm{CH}_{2} \mathrm{CH}=\mathrm{CH}_{2} \\
& \text { 6g: } \mathrm{R}=\mathrm{CH}_{2} \mathrm{CH} \\
& \text { 6h: } \mathrm{R}=\left(\mathrm{CH}_{2}\right)_{5} \mathrm{CH}_{3} \\
& \text { 6i: } \mathrm{R}=\mathrm{CH}_{2} \mathrm{COOC}_{2} \mathrm{H}_{5}
\end{aligned}
$$

Reagents and conditions: (a) Benzoyl chloride, $\mathrm{NaOH}$; (b) L-Phenylalaninol, isobutyl chloroformate (IBCF)/ $/ \mathrm{N}$-methylmorpholine (NMM), DMF- $\mathrm{CH}_{2} \mathrm{Cl}_{2} 0 \sim 5{ }^{\circ} \mathrm{C}$; (c) $\mathrm{NaOH}$, DMF, r.t.; (d) $\mathrm{HNO}_{3}$, Acetic acid, Acetic anhydride, $\mathrm{NaHCO}_{3}$, r.t.; (e) $\mathrm{NaOH}$, DMF, r.t.; (f) 2-dimethylinoethyl chloride hydrochloride or 2-diethylaminoethyl chloride hydrochloride or $n$-butyl iodide or 1-iodooctane or 1-bromopentane or allyl chloride or iodoethane or 1-bromohexane or ethyl chloroacetate, $\mathrm{K}_{2} \mathrm{CO}_{3}$, DMF, r.t.

\section{Scheme 1}


硝基- $L$-苯丙氨醇(4), 化合物 4 依次经过水解及酚羟基 的烷基化等化学反应后, 得到 11 个 MTS 衍生物 $\mathbf{6 a} \sim \mathbf{6 i}$. 所有目标产物均通过了氢谱、碳谱、质谱、元素分析等 进行结构验证, 确认与其设计结构一致.

\section{2 生物活性}

采用菼光定量 PCR 检测试剂盒检测此类化合物及 阳性对照药拉米夫定对 HepG2 2.2.15 细胞内 HBV DNA 表达量的影响. 经体外活性耖选结果显示 $6 \mathbf{d}\left(\mathrm{IC}_{50}: 6.88\right.$ $\mu \mathrm{mol} \bullet \mathrm{L}^{-1}$, SI: 12.74$)$, 6e ( $\mathrm{IC}_{50}: 37.51 \mu \mathrm{mol} \bullet \mathrm{L}^{-1}$, SI: 2.32$)$, 6g ( $\left(\mathrm{IC}_{50}: 11.07 \mu \mathrm{g} / \mathrm{mL}, \mathrm{SI}: 13.11\right)$ 等 3 个 MTS 衍生物具有 抗 HBV 活性, 并且化合物 6d 对 HepG2 2.2.15 细胞株的 抑制作用最强, 其抑制率最高, 接近阳性对照药拉米夫 定的抑制率，可对其进行进一步的研究.

\section{2 结论}

NO 供体型化合物主要用作强心剂或血管扩张剂, 在本研究中, 我们以 1-酪氨酸和苯甲酰氯为起始原料, 经酰化、缩合、水解、烷基化亲核取代等反应步骤，合 成了 11 个 $\mathrm{NO}$ 供体型马蹄金素衍生物, 并且确定其均为 设计的目标产物. 其中化合物 $\mathbf{6 d}, \mathbf{6 e}, \mathbf{6 g}$ 在 HepG2 2.2.15 细胞株上显示出相对较好的抗 HBV 活性. 构效关系表 明 1-酪氨酸的酚羟基被饱和烷基取代后, 所得产物的抑 制率相对较该酚羟基游离时的抑制率高. 其中化合物 6d 的活性最强, $8 \mu \mathrm{g} / \mathrm{mL}$ 浓度下的抑制率为 $81.3 \%$, 这为 进一步的研究提供了重要数据.

\section{3 实验部分}

\section{1 仪器与试剂}

核磁共振谱以 TMS 为内标, 用 Inova-400 MHz 型超
导核磁共振仪(美国 Varian 公司)测定; 质谱用 HP-5793 质谱仪测定(美国 Hewlett-Packard 公司); 柱色谱用硅胶 (300 400 目)及高效薄层板均为青岛海洋化工厂产品. 其余试剂均为市售分析纯或化学纯产品，除特别说明 外, 未经处理直接使用.

\section{2 化学合成}

$N$-苯甲酰基- $O$-苯甲酰基- $L$-酪氨酸(1)的合成: 取 $L$ 酪氨酸 $(5.44 \mathrm{~g}, 30 \mathrm{mmol}$ )置于冰盐浴中的反应瓶内, 加 入 $\mathrm{NaOH}$ 水溶液 $(0.5 \mathrm{~mol} / \mathrm{L}, 180 \mathrm{~mL})$, 搅拌使之溶解完 全, 缓慢滴加苯甲酰氯 $(7.0 \mathrm{~mL}, 60 \mathrm{mmol})$, 使反应液温 度维持在 $5 \sim 10{ }^{\circ} \mathrm{C}$. 滴毕反应 $4 \mathrm{~h}$, 撤去冰盐浴, 待反应 液升温至室温, 以浓 $\mathrm{HCl}$ 调节 $\mathrm{pH} 2 \sim 3$, 室温静置 $3 \sim 4$ $\mathrm{h}$, 过滤, 并以蒸馏水洗涤至 $\mathrm{pH} 5 \sim 6$, 滤饼于 $65{ }^{\circ} \mathrm{C}$ 干 燥, 得 $10.4 \mathrm{~g}$ 白色固体的化合物 $\mathbf{1}$, 产率 $89.0 \%$.

$N$ - $(N$ - 苯甲酰基- $O$-苯甲酰基- $L$-酪氨酰基)- $L$-苯丙氨 醇(2)的合成: 取化合物 1 (10.1 g, $25.9 \mathrm{mmol})$ 和 $L$-苯丙 氨醇 $(4.71 \mathrm{~g}, 31.1 \mathrm{mmol})$ 于反应瓶中, $65{ }^{\circ} \mathrm{C}$ 真空干燥 1.0 $\mathrm{h}$ 后取出, 氩气保护下, 加入 $\mathrm{DMF}(60 \mathrm{~mL}), \mathrm{CH}_{2} \mathrm{Cl}_{2}(200$ $\mathrm{mL}$ ), NMM (4 mL, $36.3 \mathrm{mmol})$, 搅拌使之完全溶解, 冰 浴冷却至 $0{ }^{\circ} \mathrm{C}$, 缓慢滴加含 $\mathrm{IBCF}(3.7 \mathrm{~mL}, 28.5 \mathrm{mmol})$ 的 $\mathrm{CH}_{2} \mathrm{Cl}_{2}$ 溶液 $100 \mathrm{~mL}$. 滴加完毕之后, 继续于 $0{ }^{\circ} \mathrm{C}$ 摚 拌 $8 \mathrm{~h}$, 加少量水终止反应, 减压回收 $\mathrm{CH}_{2} \mathrm{Cl}_{2}$ 后, 加人 水 $(500 \mathrm{~mL})$, 以 EtOAc $(500 \mathrm{~mL})$ 萃取, EtOAc 层依次以 水 $(200 \mathrm{~mL}) 、 0.1 \mathrm{~mol} / \mathrm{L}$ 盐酸 $(200 \mathrm{~mL})$ 、饱和 $\mathrm{NaHCO}_{3}$ 溶 液 $(100 \mathrm{~mL})$ 和饱和 $\mathrm{NaCl}(100 \mathrm{~mL})$ 洗涤, 有机层以无水 $\mathrm{MgSO}_{4}$ 干燥, 减压回收 EtOAc 至有大量固体析出, 冷却 过滤, 滤饼干即得 $11.4 \mathrm{~g}$ 白色固体的化合物 2, 产率 $84.1 \%$.

表 1 目标化合物对 HepG2 2.2.15 细胞内 DNA HBV 复制的抑制活性

Table 1 Inhibition for the replication of HBV DNA of compounds $4 \sim \mathbf{5}$ and $\mathbf{6} \mathbf{a} \sim \mathbf{6} \mathbf{i}$

\begin{tabular}{|c|c|c|c|c|}
\hline \multirow{2}{*}{ Compd. } & \multirow{2}{*}{ Inhibition ratio ${ }^{a} / \%$} & \multirow{2}{*}{$\mathrm{TC}_{50}{ }^{b} /\left(\mu \mathrm{mol} \cdot \mathrm{L}^{-1}\right)$} & \multicolumn{2}{|c|}{ DNA HBV replication } \\
\hline & & & $\mathrm{IC}_{50}^{c} /\left(\mu \mathrm{mol} \cdot \mathrm{L}^{-1}\right)$ & $\mathrm{SI}^{d}$ \\
\hline 4 & 31.3 & $-e$ & - & - \\
\hline 5 & 28.0 & - & - & - \\
\hline $6 a$ & 49.2 & 69.17 & 9.75 & 7.10 \\
\hline $6 b$ & 34.0 & - & - & - \\
\hline $6 c$ & 32.5 & - & - & - \\
\hline 6d & 81.3 & 87.62 & 6.88 & 12.74 \\
\hline $6 e$ & 66.6 & 86.84 & 37.51 & 2.32 \\
\hline $6 f$ & 4.7 & - & - & - \\
\hline $6 \mathrm{~g}$ & 55.6 & 145.15 & 11.07 & 13.11 \\
\hline $6 h$ & 30.5 & - & - & - \\
\hline $6 \mathbf{i}$ & 16.5 & - & - & - \\
\hline MTS & & 120.30 & 11.16 & 10.78 \\
\hline Lamivudine $^{b}$ & 98.95 & & & \\
\hline
\end{tabular}

${ }^{a}$ The inhibition ratio is tested in concentration $8 \mu \mathrm{g} \cdot \mathrm{mL}^{-1} ;{ }^{b} 50 \%$ cytotoxic concentration in $\mathrm{HepG} 22.2 .15$ cells; ${ }^{c} 50 \%$ inhibitory concentration; ${ }^{d} \mathrm{SI}=\mathrm{TC}_{50} / \mathrm{IC}_{50}$; e - : The inhibition ratio less than $50 \%$ in the test concentration range. 
$N$-( $N$-苯甲酰基- $L$-酪氨酰基)- $L$-苯丙氨醇 (3)的合成: 取化合物 2 (10.9 g, $20.9 \mathrm{mmol})$ 置于反应瓶中, 加入 DMF $(100 \mathrm{~mL})$, 室温摚拌下缓慢滴加 $\mathrm{NaOH}$ 水溶液 $(63$ $\mathrm{mL}, 1.0 \mathrm{~mol} / \mathrm{L}, 62.6 \mathrm{mmol})$. 滴加完毕后, 以 TLC 检测反 应进度, 室温摚拌反应 $4.0 \mathrm{~h}$ 后原料消失, 以浓 $\mathrm{HCl}$ 调 $\mathrm{pH} 2 \sim 3$, 加入 EtOAc $(1000 \mathrm{~mL})$ 和水 $(600 \mathrm{~mL})$ 萃取, 水 层再加入 EtOAc $(500 \mathrm{~mL})$ 萃取, 合并 EtOAc 层, 以水洗 涤(500 mL ×2), 无水 $\mathrm{MgSO}_{4}$ 干燥, 减压回收 EtOAc 至 有大量固体析出, 冷却过滤, 滤饼干燥得 $7.6 \mathrm{~g}$ 白色固体 的化合物 3, 产率 $87.1 \%{ }^{[11]}$. ${ }^{1} \mathrm{H}$ NMR (DMSO- $d_{6}, 400$ MHz) $\delta: 9.17(\mathrm{~s}, 1 \mathrm{H}, 7-\mathrm{OH}), 8.46(\mathrm{~d}, J=8.5 \mathrm{~Hz}, 1 \mathrm{H}$, 1 "-CONH), 7.90 (d, $J=8.5 \mathrm{~Hz}, 1 \mathrm{H}, 1-\mathrm{CONH}), 7.81(\mathrm{~d}$, $\left.J=7.3 \mathrm{~Hz}, 2 \mathrm{H}, \mathrm{H}-3^{\prime \prime}, 7^{\prime \prime}\right), 7.52$ (t, $J=7.2 \mathrm{~Hz}, 1 \mathrm{H}, \mathrm{H}-5^{\prime \prime}$ ), 7.45 (t, $\left.J=7.4 \mathrm{~Hz}, 2 \mathrm{H}, \mathrm{H}-4^{\prime \prime}, 6^{\prime \prime}\right), 7.23$ (d, $J=7.1 \mathrm{~Hz}, 2 \mathrm{H}$, H-5', $9^{\prime}$ ), 7.19 (t, $\left.J=7.4 \mathrm{~Hz}, 2 \mathrm{H}, \mathrm{H}-6^{\prime}, 8^{\prime}\right), 7.13$ (t, $J=7.1$ $\left.\mathrm{Hz}, 1 \mathrm{H}, \mathrm{H}-7^{\prime}\right), 7.10$ (d, $\left.J=8.2 \mathrm{~Hz}, 2 \mathrm{H}, \mathrm{H}-5,9\right), 6.63$ (t, $J=$ $8.3 \mathrm{~Hz}, 2 \mathrm{H}, \mathrm{H}-6,8), 4.84$ (t, $\left.J=5.4 \mathrm{~Hz}, 1 \mathrm{H}, 1^{\prime}-\mathrm{OH}\right), 4.61$ (td, $J=9.4,4.8 \mathrm{~Hz}, 1 \mathrm{H}, \mathrm{H}-2), 3.96 \sim 3.86\left(\mathrm{~m}, 1 \mathrm{H}, \mathrm{H}-2^{\prime}\right)$, $3.40 \sim 3.25$ (m, 2H, H-1'), 2.93 (dd, $J=4.5,13.8 \mathrm{~Hz}, 1 \mathrm{H}$, H-3a), $2.91 \sim 2.80$ (m, 2H, H-3b, 3'a), 2.68 (dd, $J=8.0$, $\left.13.6 \mathrm{~Hz}, 1 \mathrm{H}, \mathrm{H}-3^{\prime} \mathrm{b}\right)$; ESI-MS $m / z$ : $419.2[\mathrm{M}+\mathrm{H}]^{+}$.

$N$-( $N$-苯甲酰基- $O$-乙酰基- $L$-酪氨酰基)- $O$-硝基- $L$ 苯丙氨醇(4)的合成: 取化合物 $3(6.7 \mathrm{~g}, 16.0 \mathrm{mmol})$ 置于 反应瓶中, 加入乙酸 $(60 \mathrm{~mL})$, 再加入甲醇 $(20 \mathrm{~mL})$ 助溶, 搅拌使之溶解完全, 缓慢滴加含发烟硝酸 $(4.8 \mathrm{~mL})$ 和乙 酸䣶 $(1.6 \mathrm{~mL})$ 的混合溶液. 滴加完毕后, 室温摚拌反应, 以 TLC 检测反应进度, $7.5 \mathrm{~h}$ 后反应完全. 将反应液倾倒 入 $450 \mathrm{~mL}$ 的冰水中, 剧烈摚拌, 缓慢加入碳酸氢钠调 节 $\mathrm{PH}$ 至中性, 有大量黄色固体析出, 减压抽滤, 滤饼分 散在水中, 静置 $30 \mathrm{~min}$ 后抽滤, 得到的滤饼以蒸馏水洗 涤两次, 干燥滤饼, 经硅胶柱层析 [石油醚-乙酸乙酯 $(V: V=5: 1)$ 为洗脱剂 $]$ 得 $4.35 \mathrm{~g}$ 浅黄色固体化合物 $\mathbf{4}$, 产率 53.8\%. $[\alpha]_{\mathrm{D}}^{25}-31.4$ (c 1.0, $\mathrm{CHCl}_{3}$ ); ${ }^{1} \mathrm{H}$ NMR (DMSO- $\left.d_{6}, 400 \mathrm{MHz}\right) \delta: 8.57(\mathrm{~d}, J=8.4 \mathrm{~Hz}, 1 \mathrm{H}$, 1"-CONH), 8.21 (d, $J=8.0 \mathrm{~Hz}, 1 \mathrm{H}, 1-\mathrm{CONH}), 7.92$ (d, $\left.J=8.0 \mathrm{~Hz}, 2 \mathrm{H}, \mathrm{H}-3^{\prime \prime}, 7^{\prime \prime}\right), 7.86 \sim 7.77$ (m, 2H, H-4",6"), $7.55 \sim 7.01\left(\mathrm{~m}, 10 \mathrm{H}, \mathrm{H}-5^{\prime}-9^{\prime}, 5^{\prime \prime}, 5,6,8,9\right), 4.69 \sim 4.63(\mathrm{~m}$, $1 \mathrm{H}, \mathrm{H}-2), 4.22 \sim 4.17\left(\mathrm{~m}, 1 \mathrm{H}, \mathrm{H}-2^{\prime}\right), 4.07 \sim 3.98(\mathrm{~m}, 1 \mathrm{H}$, $\left.\mathrm{H}-1^{\prime} \mathrm{a}\right), 3.90 \sim 3.85\left(\mathrm{~m}, 1 \mathrm{H}, \mathrm{H}-1^{\prime} \mathrm{b}\right), 3.00 \sim 2.90(\mathrm{~m}, 2 \mathrm{H}$, $\mathrm{H}-3), 2.85 \sim 2.75$ (m, $\left.2 \mathrm{H}, \mathrm{H}-3^{\prime}\right), 2.00$ (s, $\left.3 \mathrm{H}, \mathrm{COCH}_{3}\right) ;{ }^{13} \mathrm{C}$ NMR (DMSO- $\left.d_{6}, 100 \mathrm{MHz}\right) \delta: 171.0,170.4,166.4,150.9$, $138.0,136.5,136.1,134.0,131.4,129.7,129.2,128.3$, $127.5,126.3,125.5,64.7,54.8,49.2,36.6,36.0,20.7$; ESI-MS $m / z: 528.2[\mathrm{M}+\mathrm{Na}]^{+}$. Anal. calcd for $\mathrm{C}_{27} \mathrm{H}_{27}$ $\mathrm{N}_{3} \mathrm{O}_{7}$ : C 64.15, H 5.38, N 8.31; found C 64.11, H 5.30, N
8.37.

$N$-( $N$ - 苯甲酰基- $L$-酪氨酰基)- $O$-硝基- $L$-苯丙氨醇 (5) 的合成: 取化合物 4 (4.04 g, $8.0 \mathrm{mmol})$ 置于反应瓶中, 加入 DMF $(40 \mathrm{~mL})$, 室温摚拌下缓慢滴加 $\mathrm{NaOH}$ 水溶液 $(18 \mathrm{~mL}, 1.0 \mathrm{~mol} / \mathrm{L}, 17.6 \mathrm{mmol})$. 滴加完毕后, 以 TLC 检 测反应进度, 室温摚拌反应 $2.5 \mathrm{~h}$ 后原料消失, 以浓 $\mathrm{HCl}$ 调 $\mathrm{pH} 2 \sim 3$, 加入 EtOAc $(500 \mathrm{~mL})$ 和水 $(300 \mathrm{~mL})$ 萃取, 水层再加入 $\mathrm{EtOAc}(300 \mathrm{~mL})$ 萃取, 合并 $\mathrm{EtOAc}$ 层, 水洗 涤(500 mL ×2), 无水 $\mathrm{MgSO}_{4}$ 干燥, 减压回收 EtOAc 至 有大量固体析出, 冷却过滤, 滤饼干燥得 $2.93 \mathrm{~g}$ 浅黄色 固体的化合物 5 , 产率 79.0\%. $[\alpha]_{\mathrm{D}}^{25}-24.2$ (c 1.0 , $\mathrm{CHCl}_{3}$ ); ${ }^{1} \mathrm{H}$ NMR (DMSO- $\left.d_{6}, 400 \mathrm{MHz}\right) \delta: 10.8(\mathrm{~s}, 1 \mathrm{H}$, $7-\mathrm{OH}$ ), 8.51 (d, $\left.J=8.0 \mathrm{~Hz}, 1 \mathrm{H}, 1^{\prime \prime}-\mathrm{CONH}\right), 7.96$ (d, $J=8.4$ $\mathrm{Hz}, 1 \mathrm{H}, 1-\mathrm{CONH}$ ), $7.93 \sim 7.88$ (m, 1H, H-5"), $7.80 \sim 7.74$ (m, 2H, H-3", $\left.7^{\prime \prime}\right), 7.54 \sim 7.49$ (m, 2H, H-4", $\left.6^{\prime \prime}\right), 7.46 \sim$ 7.41 (m, 2H, H-6', $\left.8^{\prime}\right), 7.22 \sim 7.14$ (m, 4H, H-5,9,5',9'), $7.11 \sim 7.08$ (m, 1H, H-7'), 7.00 (d, $J=8.4 \mathrm{~Hz}, 2 \mathrm{H}, \mathrm{H}-6,8)$, $4.66 \sim 4.62(\mathrm{~m}, 1 \mathrm{H}, \mathrm{H}-2), 3.92 \sim 3.87\left(\mathrm{~m}, 1 \mathrm{H}, \mathrm{H}-2^{\prime}\right)$, $3.34 \sim 3.27$ (m, 2H, H-1'), 3.03 (dd, $J=4.0,13.8 \mathrm{~Hz}, 1 \mathrm{H}$, H-3a), $2.94 \sim 2.83\left(\mathrm{~m}, 2 \mathrm{H}, \mathrm{H}-3 \mathrm{~b}, 3^{\prime} \mathrm{a}\right), 2.66$ (dd, $J=8.0$, $13.4 \mathrm{~Hz}, 1 \mathrm{H}, \mathrm{H}-3 \mathrm{z} b$ ); ${ }^{13} \mathrm{C}$ NMR (DMSO- $\left.d_{6}, 100 \mathrm{MHz}\right) \delta$ : $170.8,166.4,150.9,139.0,136.6,136.2,134.1,131.5$, $129.8,129.3,128.3,128.2,127.5,125.5,118.9,62.2,54.7$, 52.6, 36.5, 36.1; ESI-MS $m / z: 486.1[\mathrm{M}+\mathrm{Na}]^{+}$. Anal. calcd for $\mathrm{C}_{25} \mathrm{H}_{25} \mathrm{~N}_{3} \mathrm{O}_{6}$ : C 64.79, H 5.44, N 9.07; found $\mathrm{C}$ 64.81, H 5.38, N 9.05.

$N$ - $[N$ - 苯甲酰基- $O$-(2-二甲氨基乙基)- $L$ - 酪氨酰 基]- $O$-硝基- $L$-苯丙氨醇(6a)的合成: 取化合物 5 (464 $\mathrm{mg}, 1.0 \mathrm{mmol}$ )置于反应瓶中, 加入 DMF $(15 \mathrm{~mL})$, 摚拌 下加入无水 $\mathrm{K}_{2} \mathrm{CO}_{3}(967 \mathrm{mg}, 7.0 \mathrm{mmol})$ 、二甲氨基氯乙烷 盐酸盐 $(173 \mathrm{mg}, 1.2 \mathrm{mmol})$, 于 $100 \sim 105{ }^{\circ} \mathrm{C}$ 油浴中搅拌 $4.0 \mathrm{~h}$ 使之反应完毕(TLC 检测). 反应液冷却至室温后, 加入 EtOAc $(200 \mathrm{~mL})$ 和水 $(200 \mathrm{~mL})$ 萃取, EtOAc 层用 0.1 $\mathrm{mol} / \mathrm{L}$ 盐酸反萃取, 取酸水层, 以 $0.5 \mathrm{~mol} / \mathrm{L}$ 的 $\mathrm{NaOH}$ 水 溶液调 $\mathrm{pH} 8 \sim 9$, 加入 EtOAc $(300 \mathrm{~mL})$ 萃取, EtOAc 层水 洗一次, 无水 $\mathrm{MgSO}_{4}$ 干燥, 浓缩, 硅胶柱层析[氯仿一甲 醇 $(V: V=40: 1)$ 为洗脱剂 产率 56.7\%. $[\alpha]_{\mathrm{D}}^{25}-41.7$ (c 1.0, $\mathrm{CHCl}_{3}$ ); ${ }^{1} \mathrm{H}$ NMR (DMSO- $\left.d_{6}, 400 \mathrm{MHz}\right) \delta: 8.53(\mathrm{~d}, J=8.4 \mathrm{~Hz}, 1 \mathrm{H}$, 1 "-CONH), 7.98 (d, $J=8.0 \mathrm{~Hz}, 1 \mathrm{H}, 1-\mathrm{CONH}$ ), $7.80 \sim 7.71$ (m, 2H, H-3",7"), 7.57 (dd, J=2.4, 8.6 Hz, 1H, H-5"), $7.55 \sim 7.49$ (m, 2H, H-4", $\left.6^{\prime \prime}\right), 7.45 \sim 7.39$ (m, 2H, H-6', $8^{\prime}$ ), $7.26 \sim 7.13\left(\mathrm{~m}, 6 \mathrm{H}, \mathrm{H}-5,6,8,9,5^{\prime}, 9^{\prime}\right), 7.14 \sim 7.07(\mathrm{~m}, 1 \mathrm{H}$, H-7'), $4.68 \sim 4.62(\mathrm{~m}, 1 \mathrm{H}, \mathrm{H}-2), 4.14(\mathrm{t}, J=5.6 \mathrm{~Hz}, 2 \mathrm{H}$, 7- $\left.\mathrm{OCH}_{2} \mathrm{CH}_{2} \mathrm{~N}\left(\mathrm{CH}_{3}\right)_{2}\right), 3.93 \sim 3.88\left(\mathrm{~m}, 1 \mathrm{H}, \mathrm{H}-2^{\prime}\right), 3.34 \sim$ 
3.28 (m, 2H, H-1'), 3.03 (dd, $J=4.4,13.8 \mathrm{~Hz}, 1 \mathrm{H}, \mathrm{H}-3 \mathrm{a}$ ), $2.97 \sim 2.89$ (m, $1 \mathrm{H}, \mathrm{H}-3 \mathrm{~b}$ ), 2.83 (dd, $J=5.6,13.6 \mathrm{~Hz}, 1 \mathrm{H}$, H-3'a), 2.65 (dd, $J=8.0,13.8 \mathrm{~Hz}, 1 \mathrm{H}, \mathrm{H}-3$ 'b), 2.58 (t, $J=$ $\left.5.6 \mathrm{~Hz}, 2 \mathrm{H}, 7-\mathrm{OCH}_{2} \mathrm{CH}_{2} \mathrm{~N}\left(\mathrm{CH}_{3}\right)_{2}\right), 2.15$ (s, $6 \mathrm{H}, 7-\mathrm{OCH}_{2}-$ $\left.\mathrm{CH}_{2} \mathrm{~N}\left(\mathrm{CH}_{3}\right)_{2}\right) ;{ }^{13} \mathrm{C}$ NMR (DMSO- $\left.d_{6}, 100 \mathrm{MHz}\right) \delta: 170.8$, $166.4,150.0,139.1,139.0,135.4,134.0,131.5,131.0$, 129.3, 128.3, 128.2, 127.5, 125.5, 114.9, 67.9, 62.2, 57.3, 54.7, 52.6, 45.6, 36.5, 36.0; ESI-MS $m / z: 535.2[\mathrm{M}+\mathrm{H}]^{+}$. Anal. calcd for $\mathrm{C}_{29} \mathrm{H}_{34} \mathrm{~N}_{4} \mathrm{O}_{6}$ : C 65.15, H 6.41, N 10.48; found $\mathrm{C} 65.13, \mathrm{H} 6.37, \mathrm{~N} 10.51$.

$N$-[ $N$ - 苯甲酰基- $O$-(2-二乙氨基乙基)- $L$ - 酪氨酰 基]- $O$-硝基- $L$-苯丙氨醇(6b)的合成: 取化合物 5 (464 $\mathrm{mg}, 1.0 \mathrm{mmol}) 、 \mathrm{~K}_{2} \mathrm{CO}_{3}(967 \mathrm{mg}, 7.0 \mathrm{mmol})$ 、二乙氨基氯 乙烷盐酸盐 $(207 \mathrm{mg}, 1.2 \mathrm{mmol})$, 参照 $\mathbf{6 a}$ 的合成方法得 $213 \mathrm{mg}$ 浅黄色固体 6b, 产率 37.9\%. $[\alpha]_{\mathrm{D}}^{25}-35.5$ (c 1.0, $\mathrm{CHCl}_{3}$ ); ${ }^{1} \mathrm{H}$ NMR (DMSO- $\left.d_{6}, 400 \mathrm{MHz}\right) \delta: 8.52(\mathrm{~d}, J=8.4$ $\mathrm{Hz}, 1 \mathrm{H}, 1$ "-CONH), 7.96 (d, $J=8.4 \mathrm{~Hz}, 1 \mathrm{H}, 1-\mathrm{CONH})$, $7.81 \sim 7.75$ (m, 2H, H-3", $\left.7^{\prime \prime}\right), 7.57$ (dd, $J=2.4,8.6 \mathrm{~Hz}, 1 \mathrm{H}$, H-5"), $7.53 \sim 7.48\left(\mathrm{~m}, 2 \mathrm{H}, \mathrm{H}-4^{\prime \prime}, 6^{\prime \prime}\right), 7.45 \sim 7.41$ (m, 2H, H-6', $\left.8^{\prime}\right), 7.26 \sim 7.16$ (m, 6H, H-5,6,8,9,5',9'), 7.12 7.10 (m, 1H, H-7'), 4.68 4.63 (m, 1H, H-2), $4.12(\mathrm{t}, J=5.2$ $\left.\mathrm{Hz}, 2 \mathrm{H}, 7-\mathrm{OCH}_{2} \mathrm{CH}_{2} \mathrm{~N}\left(\mathrm{C}_{2} \mathrm{H}_{5}\right)_{2}\right), 3.92 \sim 3.87\left(\mathrm{~m}, 1 \mathrm{H}, \mathrm{H}-2^{\prime}\right)$, $3.35 \sim 3.31\left(\mathrm{~m}, 2 \mathrm{H}, \mathrm{H}-1^{\prime}\right), 3.03(\mathrm{dd}, J=4.0,14.0 \mathrm{~Hz}, 1 \mathrm{H}$, H-3a), $3.01 \sim 2.94$ (m, 1H, H-3b), 2.85 (dd, $J=5.6,13.6$ $\left.\mathrm{Hz}, 1 \mathrm{H}, \mathrm{H}-3^{\prime} \mathrm{a}\right), 2.76$ (t, $J=5.6 \mathrm{~Hz}, 2 \mathrm{H}, 7-\mathrm{OCH}_{2} \mathrm{CH}_{2-}$ $\left.\mathrm{N}\left(\mathrm{C}_{2} \mathrm{H}_{5}\right)_{2}\right), 2.66$ (dd, $\left.J=8.0,13.8 \mathrm{~Hz}, 1 \mathrm{H}, \mathrm{H}-3{ }^{\prime} \mathrm{b}\right), 2.53$ (m, $\left.4 \mathrm{H}, 7-\mathrm{OCH}_{2} \mathrm{CH}_{2} \mathrm{~N}\left(\mathrm{CH}_{2} \mathrm{CH}_{3}\right)_{2}\right), 0.91$ (t, $J=7.2 \mathrm{~Hz}, 6 \mathrm{H}$, 7- $\left.\mathrm{OCH}_{2} \mathrm{CH}_{2} \mathrm{~N}\left(\mathrm{CH}_{2} \mathrm{CH}_{3}\right)_{2}\right) ;{ }^{13} \mathrm{C}$ NMR (DMSO- $d_{6}, 100$ MHz) $\delta: 170.8,166.4,150.0,139.0,138.9,135.3,134.0$, $131.5,131.0,129.3,128.3,128.2,127.5,125.5,114.9$, 68.1, 62.2, 54.7, 52.6, 50.8, 47.1, 36.5, 36.0, 11.7; ESI-MS $m / z: 563.3[\mathrm{M}+\mathrm{H}]^{+}$. Anal. calcd for $\mathrm{C}_{31} \mathrm{H}_{38} \mathrm{~N}_{4} \mathrm{O}_{6}: \mathrm{C} 66.17$, H 6.81, N 9.96; found C 66.15, H 6.79, N 10.01 .

$N$ - $(N$ - 苯甲酰基- $O$-正丁基- $L$-酪氨酰基)- $O$-硝基- $L$ 苯丙氨醇 $(6 c)$ 的合成: 取化合物 5 (464 mg, $1.0 \mathrm{mmol})$ 置 于反应瓶中, 加入 DMF $(15 \mathrm{~mL})$ 使之溶解后, 加入无水 $\mathrm{K}_{2} \mathrm{CO}_{3}(1.38 \mathrm{~g}, 10.0 \mathrm{mmol})$, 碘代正丁烷 $(0.7 \mathrm{~mL}, 6.0$ $\mathrm{mmol}$ ), 于 $50{ }^{\circ} \mathrm{C}$ 油浴中搅拌 $4.0 \mathrm{~h}$ 使之反应完毕( TLC 检 测). 反应液冷却至室温后, 加入 EtOAc $(200 \mathrm{~mL})$ 和水 $(200 \mathrm{~mL})$ 萃取, 水层再以 EtOAc $(100 \mathrm{~mL})$ 萃取 1 次, 合 并 EtOAc 层, 水洗 1 次, 无水 $\mathrm{MgSO}_{4}$ 干燥, 浓缩, 硅胶 柱层析[石油醚-乙酸乙酯 $(V: V=5: 1)$ 为洗脱剂]得 263 $\mathrm{mg}$ 浅黄色固体 6c, 产率为 50.6\%. $[\alpha]_{\mathrm{D}}^{25}-19.4$ (c 1.0, $\mathrm{CHCl}_{3}$ ); ${ }^{1} \mathrm{H}$ NMR (DMSO- $\left.d_{6}, 400 \mathrm{MHz}\right) \delta: 8.53$ (d, $J=8.4$ $\mathrm{Hz}, 1 \mathrm{H}, 1$ "-CONH), 7.98 (d, $J=8.0 \mathrm{~Hz}, 1 \mathrm{H}, 1-\mathrm{CONH})$,
$7.79 \sim 7.74$ (m, 2H, H-3", $\left.7^{\prime \prime}\right), 7.57$ (dd, $J=2.0,8.8 \mathrm{~Hz}, 1 \mathrm{H}$, H-5"), $7.55 \sim 7.48$ (m, 2H, H-4",6"), 7.44 7.39 (m, 2H, H- $\left.6^{\prime}, 8^{\prime}\right), 7.24 \sim 7.12\left(\mathrm{~m}, 6 \mathrm{H}, \mathrm{H}-5,6,8,9,5^{\prime}, 9^{\prime}\right), 7.12 \sim 7.08$ (m, 1H, H-7'), 4.69 4.64 (m, 1H, H-2), 4.05 (t, $J=6.0$ $\left.\mathrm{Hz}, 2 \mathrm{H}, 7-\mathrm{OCH}_{2}\left(\mathrm{CH}_{2}\right)_{2} \mathrm{CH}_{3}\right), 3.93 \sim 3.86\left(\mathrm{~m}, 1 \mathrm{H}, \mathrm{H}-2^{\prime}\right)$, $3.32 \sim 3.27$ (m, 2H, H-1'), 3.03 (dd, $J=4.4,13.6 \mathrm{~Hz}, 1 \mathrm{H}$, H-3a), $2.95 \sim 2.89$ (m, 1H, H-3b), 2.85 (dd, $J=6.0,13.6$ $\left.\mathrm{Hz}, 1 \mathrm{H}, \mathrm{H}-3^{\prime} \mathrm{a}\right), 2.66$ (dd, $J=8.0,13.8 \mathrm{~Hz}, 1 \mathrm{H}, \mathrm{H}-3^{\prime} \mathrm{b}$ ), $1.65 \sim 1.61\left(\mathrm{~m}, 2 \mathrm{H}, 7-\mathrm{OCH}_{2} \mathrm{CH}_{2} \mathrm{CH}_{2} \mathrm{CH}_{3}\right), 1.39 \sim 1.34(\mathrm{~m}$, $\left.2 \mathrm{H}, 7-\mathrm{O}\left(\mathrm{CH}_{2}\right)_{2} \mathrm{CH}_{2} \mathrm{CH}_{3}\right), 0.87$ (t, $J=7.6 \mathrm{~Hz}, 3 \mathrm{H}, 7-\mathrm{O}-$ $\left(\mathrm{CH}_{2}\right)_{3} \mathrm{CH}_{3}$ ); ${ }^{13} \mathrm{C}$ NMR (DMSO- $\left.d_{6}, 100 \mathrm{MHz}\right) \delta$ : 170.7, $166.3,150.1,139.0,135.4,134.0,131.5,130.8,129.3$, $128.3,128.2,127.5,125.5,114.8,68.8,62.2,54.7,52.6$, 36.5, 36.0, 30.5, 18.6, 13.6; ESI-MS $m / z$ : $542.2[\mathrm{M}+\mathrm{Na}]^{+}$. Anal. calcd for $\mathrm{C}_{29} \mathrm{H}_{33} \mathrm{~N}_{3} \mathrm{O}_{6}$ : C 67.04, H 6.40, $\mathrm{N}$ 8.09; found $\mathrm{C} 67.06, \mathrm{H} 6.38, \mathrm{~N} 8.07$.

$\mathrm{N}$-( $\mathrm{N}$-苯甲酰基- $O$-正辛基 $-\mathrm{L}$-酪氨酰基)- $O$-硝基- $L$ 苯丙氨醇 $(6 \mathbf{d})$ 的合成: 取化合物 $5(464 \mathrm{mg}, 1.0 \mathrm{mmol})$ 、 无水 $\mathrm{K}_{2} \mathrm{CO}_{3}(1.38 \mathrm{~g}, 10.0 \mathrm{mmol}) 、$ 碘代正辛烷 $(1.1 \mathrm{~mL}, 6.0$ $\mathrm{mmol})$, 参照 $\mathbf{6 c}$ 的方法得 $312 \mathrm{mg}$ 浅黄色固体 $\mathbf{6 d}$, 产率 $54.2 \%$. $[\alpha]_{\mathrm{D}}^{25}-21.9\left(c 1.0, \mathrm{CHCl}_{3}\right) ;{ }^{1} \mathrm{H}$ NMR (DMSO- $d_{6}$, $400 \mathrm{MHz}) \delta: 8.52$ (d, $\left.J=8.8 \mathrm{~Hz}, 1 \mathrm{H}, 1^{\prime \prime}-\mathrm{CONH}\right), 7.96$ (d, $J=8.4 \mathrm{~Hz}, 1 \mathrm{H}, 1-\mathrm{CONH}), 7.82 \sim 7.77$ (m, 2H, H-3", $7^{\prime \prime}$ ), $7.53 \sim 7.47$ (dd, $\left.J=2.0,8.6 \mathrm{~Hz}, 1 \mathrm{H}, \mathrm{H}-5^{\prime \prime}\right), 7.53 \sim 7.47$ (m, $\left.2 \mathrm{H}, \mathrm{H}-4^{\prime \prime}, 6^{\prime \prime}\right), 7.45 \sim 7.39$ (m, 2H, H-6', $\left.8^{\prime}\right), 7.23 \sim 7.13$ (m, $\left.6 \mathrm{H}, \mathrm{H}-5,6,8,9,5^{\prime}, 9^{\prime}\right), 7.13 \sim 7.08$ ( $\left.\mathrm{m}, 1 \mathrm{H}, \mathrm{H}-7^{\prime}\right), 4.68 \sim 4.63$ (m, $1 \mathrm{H}, \mathrm{H}-2), 4.04$ (t, $J=6.4 \mathrm{~Hz}, 2 \mathrm{H}, 7-\mathrm{OCH}_{2}\left(\mathrm{CH}_{2}\right)_{6} \mathrm{CH}_{3}$ ), $3.92 \sim 3.85\left(\mathrm{~m}, 1 \mathrm{H}, \mathrm{H}-2^{\prime}\right), 3.35 \sim 3.29$ (m, 2H, H-1'), 3.03 (dd, $J=3.6,13.6 \mathrm{~Hz}, 1 \mathrm{H}, \mathrm{H}-3 \mathrm{a}), 2.97 \sim 2.93(\mathrm{~m}, 1 \mathrm{H}$, H-3b), 2.85 (dd, $J=6.0,13.6 \mathrm{~Hz}, 1 \mathrm{H}, \mathrm{H}-3$ 'a), 2.66 (dd, $J=$ $\left.8.0,13.8 \mathrm{~Hz}, 1 \mathrm{H}, \mathrm{H}-3^{\prime} \mathrm{b}\right), 1.67 \sim 1.62\left(\mathrm{~m}, 2 \mathrm{H}, 7-\mathrm{OCH}_{2} \mathrm{CH}_{2}-\right.$ $\left.\left(\mathrm{CH}_{2}\right)_{5} \mathrm{CH}_{3}\right), \quad 1.36 \sim 1.30\left(\mathrm{~m}, 2 \mathrm{H}, 7-\mathrm{O}\left(\mathrm{CH}_{2}\right)_{2} \mathrm{CH}_{2}\left(\mathrm{CH}_{2}\right)_{4}-\right.$ $\left.\mathrm{CH}_{3}\right), 1.25 \sim 1.19\left(\mathrm{~m}, 8 \mathrm{H}, 7-\mathrm{O}\left(\mathrm{CH}_{2}\right)_{3}\left(\mathrm{CH}_{2}\right)_{4} \mathrm{CH}_{3}\right), 0.82(\mathrm{t}$, $J=7.2 \mathrm{~Hz}, 3 \mathrm{H}, 7-\mathrm{O}\left(\mathrm{CH}_{2}\right)_{3} \mathrm{CH}_{3}$ ); ${ }^{13} \mathrm{C}$ NMR (DMSO- $d_{6}, 100$ MHz) $\delta:$ 170.7, 166.3, 150.1, 139.0, 135.3, 134.0, 131.4, $130.8,129.3,128.3,128.2,127.5,125.5,114.8,69.1,62.2$, 54.7, 52.6, 36.5, 36.0, 31.2, 28.7, 28.6, 28.4, 25.3, 22.1, 14.0; ESI-MS $m / z$ : $598.2[\mathrm{M}+\mathrm{Na}]^{+}$. Anal. calcd for $\mathrm{C}_{33} \mathrm{H}_{41} \mathrm{~N}_{3} \mathrm{O}_{6}$ : C 68.85, H 7.18, N 7.30; found C 68.84, H 7.20, N 7.32.

$N$-( $N$ - 苯甲酰基- $O$-正戊基- $L$-酪氨酰基)- $O$-硝基- $L$ 苯丙氨醇(6e)的合成: 取化合物 $5(464 \mathrm{mg}, 1.0 \mathrm{mmol})$ 、 无水 $\mathrm{K}_{2} \mathrm{CO}_{3}(1.38 \mathrm{~g}, 10.0 \mathrm{mmol}) 、$ 溴代正戊烷 $(0.9 \mathrm{~mL}, 6.0$ $\mathrm{mmol}$ ), 参照 $\mathbf{6 c}$ 的方法得 $367 \mathrm{mg}$ 浅黄色固体 $\mathbf{6 e}$, 产率 68.8\%. $[\alpha]_{\mathrm{D}}^{25}-20.8\left(c 1.0, \mathrm{CHCl}_{3}\right) ;{ }^{1} \mathrm{H}$ NMR (DMSO- $d_{6}$, 
$400 \mathrm{MHz}) \delta: 8.52$ (d, $\left.J=8.8 \mathrm{~Hz}, 1 \mathrm{H}, 1^{\prime \prime}-\mathrm{CONH}\right), 7.96(\mathrm{~d}$, $J=8.4 \mathrm{~Hz}, 1 \mathrm{H}, 1-\mathrm{CONH}), 7.81 \sim 7.77$ (m, 2H, H-3", $\left.7^{\prime \prime}\right)$, 7.57 (dd, $\left.J=2.0,8.6 \mathrm{~Hz}, 1 \mathrm{H}, \mathrm{H}-5^{\prime \prime}\right), 7.53 \sim 7.49(\mathrm{~m}, 2 \mathrm{H}$, H-4", $6^{\prime \prime}$ ), $7.44 \sim 7.39$ (m, 2H, H-6', $\left.8^{\prime}\right), 7.23 \sim 7.12$ (m, 6H, H-5,6,8,9,5', $\left.9^{\prime}\right), 7.11 \sim 7.07$ (m, 1H, H-7'), 4.69 4.62 (m, $1 \mathrm{H}, \mathrm{H}-2), 4.05$ (t, $\left.J=6.4 \mathrm{~Hz}, 2 \mathrm{H}, 7-\mathrm{OCH}_{2}\left(\mathrm{CH}_{2}\right)_{3} \mathrm{CH}_{3}\right)$, $3.93 \sim 3.88\left(\mathrm{~m}, 1 \mathrm{H}, \mathrm{H}-2^{\prime}\right), 3.33 \sim 3.30\left(\mathrm{~m}, 2 \mathrm{H}, \mathrm{H}-1^{\prime}\right), 3.04$ (dd, $J=4.4,13.6 \mathrm{~Hz}, 1 \mathrm{H}, \mathrm{H}-3 \mathrm{a}), 3.01 \sim 2.92(\mathrm{~m}, 1 \mathrm{H}$, H-3b), 2.85 (dd, $J=5.6,14.2 \mathrm{~Hz}, 1 \mathrm{H}, \mathrm{H}-3$ 'a), 2.66 (dd, $J=$ $\left.8.4,13.8 \mathrm{~Hz}, 1 \mathrm{H}, \mathrm{H}-3^{\prime} \mathrm{b}\right), 1.69 \sim 1.62\left(\mathrm{~m}, 2 \mathrm{H}, 7-\mathrm{OCH}_{2} \mathrm{CH}_{2}-\right.$ $\left.\left(\mathrm{CH}_{2}\right)_{2} \mathrm{CH}_{3}\right), 1.37 \sim 1.21\left(\mathrm{~m}, 4 \mathrm{H}, 7-\mathrm{O}\left(\mathrm{CH}_{2}\right)_{2}\left(\mathrm{CH}_{2}\right)_{2} \mathrm{CH}_{3}\right)$, 0.82 (t, $\left.J=7.2 \mathrm{~Hz}, 3 \mathrm{H}, 7-\mathrm{O}\left(\mathrm{CH}_{2}\right)_{4} \mathrm{CH}_{3}\right) ;{ }^{13} \mathrm{C}$ NMR (DMSO- $\left.d_{6}, 100 \mathrm{MHz}\right) \delta: 170.8,166.4,150.1,139.0,135.4$, $134.0,131.5,130.8,129.3,128.3,128.2,127.5,125.5$, $114.8,69.1,62.2,54.7$ (C-2), 52.6, 36.5, 36.0, 28.1, 27.6, 21.8, 14.0; ESI-MS $m / z: 556.3[\mathrm{M}+\mathrm{Na}]^{+}$. Anal. calcd for $\mathrm{C}_{30} \mathrm{H}_{35} \mathrm{~N}_{3} \mathrm{O}_{6}$ : C 67.52, H 6.61, N 7.87; found C 67.51, H 6.63, N 7.88 .

$N$-( $N$ - 苯甲酰基- $O$-丙烯基- $L$-酪氨酰基)- $O$-硝基- $L$ 苯丙氨醇 $(\mathbf{6 f})$ 的合成: 取化合物 5 (464 mg, $1.0 \mathrm{mmol})$ 、无 水 $\mathrm{K}_{2} \mathrm{CO}_{3}(1.38 \mathrm{~g}, 10.0 \mathrm{mmol}) 、$ 氯丙烯 $(0.7 \mathrm{~mL}, 6.0 \mathrm{mmol})$, 参照 $\mathbf{6 c}$ 的方法得 $172 \mathrm{mg}$ 浅黄色固体 $\mathbf{6 f}$, 产率 $34.2 \%$. $[\alpha]_{\mathrm{D}}^{25}-25.6$ (c 1.0, $\mathrm{CHCl}_{3}$ ); ${ }^{1} \mathrm{H}$ NMR (DMSO- $d_{6}, 400$ MHz) $\delta$ : 8.52 (d, $\left.J=8.4 \mathrm{~Hz}, 1 \mathrm{H}, 1^{\prime \prime}-\mathrm{CONH}\right), 7.95$ (d, $J=$ $8.8 \mathrm{~Hz}, 1 \mathrm{H}, 1-\mathrm{CONH}), 7.81 \sim 7.75$ (m, 2H, H-3", $\left.7^{\prime \prime}\right), 7.57$ (dd, $\left.J=2.0,8.8 \mathrm{~Hz}, 1 \mathrm{H}, \mathrm{H}-5^{\prime \prime}\right), 7.55 \sim 7.48(\mathrm{~m}, 2 \mathrm{H}$, H-4", $\left.6^{\prime \prime}\right), 7.45 \sim 7.41$ (m, 2H, H-6', $\left.8^{\prime}\right), 7.25 \sim 7.13$ (m, 6H, H-5,6,8,9,5', $\left.9^{\prime}\right), 7.11 \sim 7.09$ (m, 1H, H-7'), 6.01 5.96 (m, $\left.1 \mathrm{H}, 7-\mathrm{OCH}_{2} \mathrm{CH}=\mathrm{CH}_{2}\right), 5.41 \sim 5.37\left(\mathrm{~m}, 1 \mathrm{H}, 7-\mathrm{OCH}_{2} \mathrm{CH}=\right.$ $\mathrm{CHH}), 5.25 \sim 5.21\left(\mathrm{~m}, 1 \mathrm{H}, 7-\mathrm{OCH}_{2} \mathrm{CH}=\mathrm{CHH}\right), 4.84(\mathrm{t}$, $J=5.6 \mathrm{~Hz}, 1 \mathrm{H}, \mathrm{H}-2), 4.67 \sim 4.62\left(\mathrm{~m}, 2 \mathrm{H}, 7-\mathrm{OCH}_{2} \mathrm{CH}=\right.$ $\left.\mathrm{CH}_{2}\right), 3.91 \sim 3.89\left(\mathrm{~m}, 1 \mathrm{H}, \mathrm{H}-2^{\prime}\right), 3.34 \sim 3.28\left(\mathrm{~m}, 2 \mathrm{H}, \mathrm{H}-\mathrm{l}^{\prime}\right)$, 3.04 (dd, $J=4.8,13.6 \mathrm{~Hz}, 1 \mathrm{H}, \mathrm{H}-3 \mathrm{a}), 2.99 \sim 2.90(\mathrm{~m}, 1 \mathrm{H}$, H-3b), 2.85 (dd, $J=5.6,14.0 \mathrm{~Hz}, 1 \mathrm{H}, \mathrm{H}-3$ 'a), 2.65 (dd, $J=$ 8.0, $13.6 \mathrm{~Hz}, 1 \mathrm{H}, \mathrm{H}-3 \mathrm{\prime}$ ) $) ;{ }^{13} \mathrm{C}$ NMR (DMSO- $d_{6}, 100 \mathrm{MHz}$ ) $\delta: 170.7,166.3,149.5,139.0,135.3,134.0,132.6,131.4$, $131.2,129.3,128.3,128.2,127.5,125.6,117.9,115.1$, 69.4, 62.2, 54.7, 52.6, 36.5, 36.0; ESI-MS $m / z$ : $526.2[\mathrm{M}+$ $\mathrm{Na}]^{+}$. Anal. calcd for $\mathrm{C}_{28} \mathrm{H}_{29} \mathrm{~N}_{3} \mathrm{O}_{6}: \mathrm{C} 66.79, \mathrm{H} 5.80, \mathrm{~N}$ 8.34; found C 66.80, H 5.77, N 8.37.

$N$-( $N$-苯甲酰基- $O$-乙基- $L$-酪氨酰基)- $O$-硝基- $L$-苯 丙氨醇 $(\mathbf{6 g})$ 的合成: 取化合物 $5(464 \mathrm{mg}, 1.0 \mathrm{mmol})$ 、无 水 $\mathrm{K}_{2} \mathrm{CO}_{3}(1.38 \mathrm{~g}, 10.0 \mathrm{mmol})$ 、碘乙烷 $(0.5 \mathrm{~mL}, 6.0 \mathrm{mmol})$, 参照 $6 \mathbf{c}$ 的方法得 $143 \mathrm{mg}$ 浅黄色固体 $\mathbf{6 g}$, 产率 $29.1 \%$. $[\alpha]_{\mathrm{D}}^{25}-19.9$ (c 1.0, $\mathrm{CHCl}_{3}$ ); ${ }^{1} \mathrm{H}$ NMR (DMSO- $d_{6}, 400$
MHz) $\delta: 8.52$ (d, $\left.J=8.4 \mathrm{~Hz}, 1 \mathrm{H}, 1^{\prime \prime}-\mathrm{CONH}\right), 7.99$ (d, $J=$ $8.0 \mathrm{~Hz}, 1 \mathrm{H}, 1-\mathrm{CONH}$ ), $7.81 \sim 7.77$ (m, 2H, H-3", $\left.7^{\prime \prime}\right), 7.58$ (dd, $\left.J=2.2,8.8 \mathrm{~Hz}, 1 \mathrm{H}, \mathrm{H}-5^{\prime \prime}\right), 7.55 \sim 7.49(\mathrm{~m}, 2 \mathrm{H}$, H-4", $6^{\prime \prime}$ ), $7.44 \sim 7.39$ (m, 2H, H-6', $\left.8^{\prime}\right), 7.24 \sim 7.13$ (m, 6H, H-5,6,8,9,5', $\left.9^{\prime}\right), 7.13 \sim 7.05$ (m, 1H, H-7'), 4.70 4.62 (m, $1 \mathrm{H}, \mathrm{H}-2), 4.12 \sim 4.05\left(\mathrm{~m}, 2 \mathrm{H}, 7-\mathrm{OCH}_{2} \mathrm{CH}_{3}\right), 3.93 \sim 3.84$ (m, 1H, H-2'), 3.33 3.27 (m, 2H, H-1'), 3.02 (dd, $J=4.2$, $13.8 \mathrm{~Hz}, 1 \mathrm{H}, \mathrm{H}-3 \mathrm{a}$ ), $3.01 \sim 2.92$ (m, 1H, H-3b), 2.84 (dd, $\left.J=6.0,13.6 \mathrm{~Hz}, 1 \mathrm{H}, \mathrm{H}-3^{\prime} \mathrm{a}\right), 2.65$ (dd, $J=8.2,13.6 \mathrm{~Hz}, 1 \mathrm{H}$, $\mathrm{H}-3$ 'b), 1.17 (t, $\left.J=7.4 \mathrm{~Hz}, 3 \mathrm{H}, 7-\mathrm{O}\left(\mathrm{CH}_{2}\right)_{3} \mathrm{CH}_{3}\right) ;{ }^{13} \mathrm{C} \mathrm{NMR}$ (DMSO- $\left.d_{6}, 100 \mathrm{MHz}\right) \delta: 171.1,166.8,150.2,139.0,136.1$, $135.4,134.0,131.5,130.8,129.2,128.3,128.2,127.5$, $125.5,114.8,68.5,62.1,54.9,52.6,36.5,36.0,14.4$; ESI-MS $\mathrm{m} / z$ : $514.2[\mathrm{M}+\mathrm{Na}]^{+}$. Anal. calcd for $\mathrm{C}_{27} \mathrm{H}_{29^{-}}$ $\mathrm{N}_{3} \mathrm{O}_{6}$ : C 65.97, H 5.95, N 8.55; found C 65.95, H 5.96, N 8.53 .

$\mathrm{N}$-( $\mathrm{N}$ - 苯甲酰基- $O$-正己基- $\mathrm{L}$-酪氨酰基)- $O$-硝基- $\mathrm{L}$ 苯丙氨醇 $(\mathbf{6 h})$ 的合成: 取化合物 5 (464 mg, $1.0 \mathrm{mmol})$ 、 无水 $\mathrm{K}_{2} \mathrm{CO}_{3}(1.38 \mathrm{~g}, 10.0 \mathrm{mmol})$ 、溴代正己烷 $(1.0 \mathrm{~mL}, 7.0$ $\mathrm{mmol}$ ), 参照 $\mathbf{6 c}$ 的方法得 $471 \mathrm{mg}$ 浅黄色固体 $\mathbf{6 h}$, 产率 $86.0 \%$ \% $[\alpha]_{\mathrm{D}}^{25}-15.7\left(c 1.0, \mathrm{CHCl}_{3}\right) ;{ }^{1} \mathrm{H}$ NMR (DMSO- $d_{6}$, $400 \mathrm{MHz}) \delta: 8.50\left(\mathrm{~d}, J=8.8 \mathrm{~Hz}, 1 \mathrm{H}, 1^{\prime \prime}-\mathrm{CONH}\right), 7.94(\mathrm{~d}$, $J=8.4 \mathrm{~Hz}, 1 \mathrm{H}, 1-\mathrm{CONH}), 7.84$ (d, $\left.J=2.0 \mathrm{~Hz}, 1 \mathrm{H}, \mathrm{H}-5^{\prime \prime}\right)$, 7.77 (d, $\left.J=7.2 \mathrm{~Hz}, 2 \mathrm{H}, \mathrm{H}-3^{\prime \prime}, 7^{\prime \prime}\right), 7.56$ (dd, $J=2.0,8.8 \mathrm{~Hz}$, $\left.1 \mathrm{H}, \mathrm{H}-8^{\prime}\right), 7.51$ (t, $\left.J=7.2 \mathrm{~Hz}, 1 \mathrm{H}, \mathrm{H}-7^{\prime}\right), 7.43$ (t, $J=8.0$ $\left.\mathrm{Hz}, 2 \mathrm{H}, \mathrm{H}-4^{\prime \prime}, 6^{\prime \prime}\right), 7.23 \sim 7.16$ (m, 6H, H-5,6,8,9,5',9'), $7.14 \sim 7.09$ (m, 1H, H-6'), 4.67 4.63 (m, 1H, H-2), 4.05 $\left(\mathrm{t}, J=6.4 \mathrm{~Hz}, 2 \mathrm{H}, 7-\mathrm{OCH}_{2}\left(\mathrm{CH}_{2}\right)_{4} \mathrm{CH}_{3}\right), 3.94 \sim 3.89(\mathrm{~m}, 1 \mathrm{H}$, $\left.\mathrm{H}-2^{\prime}\right), 3.36 \sim 3.30\left(\mathrm{~m}, 2 \mathrm{H}, \mathrm{H}-1^{\prime}\right), 3.06 \sim 2.83(\mathrm{~m}, 4 \mathrm{H}$, $\left.\mathrm{H}-3,3^{\prime}\right), \quad 1.63 \sim 1.59\left(\mathrm{~m}, 2 \mathrm{H}, \quad 7-\mathrm{OCH}_{2} \mathrm{CH}_{2}\left(\mathrm{CH}_{2}\right)_{3} \mathrm{CH}_{3}\right)$, $1.37 \sim 1.29\left(\mathrm{~m}, 2 \mathrm{H}, 7-\mathrm{O}\left(\mathrm{CH}_{2}\right)_{2} \mathrm{CH}_{2}\left(\mathrm{CH}_{2}\right)_{2} \mathrm{CH}_{3}\right), 1.25 \sim 1.19$ (m, 4H, 7-O $\left.\left(\mathrm{CH}_{2}\right)_{3}\left(\mathrm{CH}_{2}\right)_{2} \mathrm{CH}_{3}\right), 0.82(\mathrm{t}, J=6.8 \mathrm{~Hz}, 3 \mathrm{H}$, $\left.7-\mathrm{O}\left(\mathrm{CH}_{2}\right)_{5} \mathrm{CH}_{3}\right) ;{ }^{13} \mathrm{C}$ NMR (DMSO- $\left.d_{6}, 100 \mathrm{MHz}\right) \delta: 170.7$, $166.4,150.1,139.0,135.4,134.0,131.5,130.8,129.3$, $128.3,128.2,127.5,126.0,125.5,114.8,69.1,62.2,54.7$, 52.6, 38.9, 36.5, 30.9, 28.4, 25.0, 22.1, 13.9; ESI-MS $m / z$ : $570.2[\mathrm{M}+\mathrm{Na}]^{+}$. Anal. calcd for $\mathrm{C}_{31} \mathrm{H}_{37} \mathrm{~N}_{3} \mathrm{O}_{6}: \mathrm{C} 67.99, \mathrm{H}$ 6.81, N 7.67; found C 68.01, H 6.80, N 7.66.

$\mathrm{N}$-( $\mathrm{N}$ - 苯甲酰基- $\mathrm{O}$-乙酸乙酯基- $\mathrm{L}$-酪氨酰基)- $O$-硝 基-1-苯丙氨醇 (6i) 的合成: 取化合物 5 (464 mg, 1.0 $\mathrm{mmol}) 、$ 无水 $\mathrm{K}_{2} \mathrm{CO}_{3}(1.38 \mathrm{~g}, 10.0 \mathrm{mmol}) 、$ 氯乙酸乙酯 $(1.5$ $\mathrm{mL}, 7.0 \mathrm{mmol}$ ), 参照 $\mathbf{6 c}$ 的方法得 $375 \mathrm{mg}$ 浅黄色固体 $\mathbf{6 i}$, 产率 $34.1 \%$. $[\alpha]_{\mathrm{D}}^{25}-16.6$ (c 1.0, $\mathrm{CHCl}_{3}$ ); ${ }^{1} \mathrm{H}$ NMR $\left(\right.$ DMSO- $\left.d_{6}, 400 \mathrm{MHz}\right) \delta: 8.56(\mathrm{~d}, J=8.4 \mathrm{~Hz}, 1 \mathrm{H}$, 1"-CONH), 8.22 (d, $J=8.0 \mathrm{~Hz}, 1 \mathrm{H}, 1-\mathrm{CONH}), 7.87$ (d, 
$\left.J=2.4 \mathrm{~Hz}, 1 \mathrm{H}, \mathrm{H}-5^{\prime \prime}\right), 7.80 \sim 7.77$ (m, 2H, H-3", $\left.7^{\prime \prime}\right), 7.55$ (dd, $\left.J=2.0,9.0 \mathrm{~Hz}, 1 \mathrm{H}, \mathrm{H}-8^{\prime}\right), 7.55 \sim 7.50\left(\mathrm{~m}, 1 \mathrm{H}, \mathrm{H}-7^{\prime}\right)$, $7.46 \sim 7.39\left(\mathrm{~m}, 2 \mathrm{H}, \mathrm{H}-4^{\prime \prime}, 6^{\prime \prime}\right), 7.27 \sim 7.19(\mathrm{~m}, 4 \mathrm{H}$, H-5,9,5', $\left.9^{\prime}\right), 7.16 \sim 7.12$ (m, 3H, H-6,8,6'), 4.93 (s, 2H, $7-\mathrm{OCH}_{2} \mathrm{COOC}_{2} \mathrm{H}_{5}$ ), $4.70 \sim 4.61(\mathrm{~m}, 1 \mathrm{H}, \mathrm{H}-2), 4.22 \sim 4.15$ (m, $\left.2 \mathrm{H}, 7-\mathrm{OCH}_{2} \mathrm{COOCH}_{2} \mathrm{CH}_{3}\right), 4.12 \sim 4.03\left(\mathrm{~m}, 2 \mathrm{H}, \mathrm{H}-1^{\prime}\right)$, $4.00 \sim 3.94\left(\mathrm{~m}, 1 \mathrm{H}, \mathrm{H}-2^{\prime}\right), 3.03 \sim 2.97(\mathrm{~m}, 2 \mathrm{H}, \mathrm{H}-3)$, $2.84 \sim 2.74\left(\mathrm{~m}, 2 \mathrm{H}, \mathrm{H}-3^{\prime}\right), 1.13(\mathrm{t}, J=6.8 \mathrm{~Hz}, 3 \mathrm{H}$, 7- $\mathrm{OCH}_{2} \mathrm{COOCH}_{2} \mathrm{CH}_{3}$ ); ${ }^{13} \mathrm{C}$ NMR (DMSO- $\left.d_{6}, 100 \mathrm{MHz}\right) \delta$ : $171.1,168.0,167.4,149.1,139.2,135.1,134.0,131.9$, $131.5,129.2,128.4,128.3,127.5,126.4,125.5,115.1$, 66.0, 65.6, 61.0, 54.7, 49.1, 41.2, 36.4, 14.0; ESI-MS $m / z$ : $550.3[\mathrm{M}+\mathrm{H}]^{+}$. Anal. calcd for $\mathrm{C}_{29} \mathrm{H}_{31} \mathrm{~N}_{3} \mathrm{O}_{8}: \mathrm{C} 63.38, \mathrm{H}$ 5.69, N 7.65; found C 63.34, H 5.67, N 7.67.

\section{3 抗 HBV 活性实验}

\subsubsection{MTT 法测定药物对细胞的毒性}

HepG2 2.2.15 细胞培养瓶长满细胞后, 经消化, 配 制成每毫升 20 万个细胞, 接种 96 孔培养板, 每孔 100 $\mu \mathrm{L}$, 培养 $24 \mathrm{~h}$ 细胞贴壁后给药, 每孔给 $200 \mu \mathrm{L}$ 药液, 设 $320,160,80,40,20 \mu \mathrm{g} \cdot \mathrm{mL}^{-1}$ 这 5 个浓度, 每浓度 3 个孔, 设以培养液代替药液的细胞对照组. $37{ }^{\circ} \mathrm{C}, 5 \% \mathrm{CO}_{2}$ 培 养, 每天换同浓度药液. 培养 $3 \mathrm{~d}$ 每孔加入 $20 \mu \mathrm{L}$ MTT 溶液 $\left(5 \mathrm{mg} \cdot \mathrm{mL}^{-1}\right), 37{ }^{\circ} \mathrm{C}, 5 \% \mathrm{CO}_{2}$ 培养 $4 \mathrm{~h}$, 吸去培养液, 加入 $200 \mu \mathrm{L} \mathrm{DMSO}$, 振荡 $10 \mathrm{~min}$, 使结晶溶解, 在酶联 免疫检测仪上 $450 \mathrm{~nm} / 630 \mathrm{~nm}$ 波长下测定光吸收值, 计 算半数有毒浓度 $\left(\mathrm{TC}_{50}\right)^{[19,20]}$.

\subsection{2 药物对 HBV DNA 抑制试验}

HepG2 2.2.15 细胞每毫升 20 万个接种 24 孔细胞培 养板, 每孔 $500 \mu \mathrm{L}$, 贴壁 $24 \mathrm{~h}$ 后给药, 每孔 $700 \mu \mathrm{L}$ 药液, 样品共设 $20,8,3.2,1.28 \mu \mathrm{g} \cdot \mathrm{mL}^{-1}$ 等 4 个浓度, 每浓度 3 孔, 以加等量 DMSO 的培养液代替药液的细胞为对照 组, 拉米夫定为阳性对照, 浓度设为 $8 \mu \mathrm{g} \cdot \mathrm{mL}^{-1}$. 每 $3 \mathrm{~d}$
换原浓度药液培养, $6 \mathrm{~d}$ 后提取 HBV DNA, 经荧光定量 PCR 测定其 DNA 含量, 通过含量测定结果计算样品对 细胞中 HBV DNA 复制的抑制率, 计算半数抑制浓度 $\left(\mathrm{IC}_{50}\right)$.

致谢 本文中的所有核磁谱图数据由贵州省中国科学 院天然产物化学重点实验室张建新老师测试、提供, 在 此表示衰心的感谢.

\section{References}

[1] Lin, K. W.; Kirchner, J. T. Am. Fam. Physicianitis 2004, 69(1), 75.

[2] Lavanchy, D. J. Viral Hepat. 2004, $11(2), 97$.

[3] Kennedy, M.; Alexopoulos, S. P. Curr. Opin. Organ Transplant. 2010, 15(3), 310.

[4] Cuestas, M. L.; Mathet, V. L.; Oubina, J. R. Pharm. Res. 2010, 27(7), 1184.

[5] Kumar, R.; Agrawal, B. Curr. Opin. Invest. Drugs 2004, 5(2), 171.

[6] Shaw, T.; Bartholomeusz, A.; Locarnini, S. J. Hepatol. 2006, 44(3), 593.

[7] Colonno, R. T.; Rose, R. E.; Pokornowski, K. J. Hepatol. 2007, 46(S1), 294.

[8] Lai, C.-L.; Gane, E.; Hsu, C. W. Hepatology 2006, 44(S1), 222.

[9] Xu, B-X.; Huang, Z-M.; Liu, C-X. Bioorg. Med. Chem. 2009, 17(8), 3118.

[10] Qiu, J.-Y.; Xu, B.-X.; Huang, Z.-M. Bioorg. Med. Chem. 2011, $19(18), 5352$.

[11] Liang, G.-P.; Hu, Z.-X.; Liang G.-Y. Fine Chem. 2013, 30(8), 925 (in Chinese).

(梁光平, 胡占兴, 梁光义, 精细化工, 2013, 30(8), 925.)

[12] Mombouli, J. V.; Vanhoutte, P. M. J. Mol. Cell. Cardiol. 1999, $31(1), 61$.

[13] Kerwin, J. F. Jr.; Heller, M. Med. Res. Rev. 1994, 14(1): 23.

[14] Carol, S. R.; Takashi, K. J. Virol. 1998, 72(6), 4547.

[15] Meier, C.; Lorey, M.; De, C. J. Med. Chem. 1998, 41, 1417.

[16] Naimi, E.; Zhou, A.; Khalili, P. J. Med. Chem. 2003, 46, 995.

[17] Samuel, K. K.; Nicolas, B.; Amy, P. J. Med. Chem. 2013, 56, 9517.

[18] Deng, Y.-J.; Shi, J.-B.; Jiang, L.-X. Acta Chim. Sinica 2006, 64(18), 1911 (in Chinese).

(邓艳君, 石静波, 姜力勋, 化学学报, 2006, 64(18), 1911.)

[19] Korba, B. E.; Gerin, J. L. Antiviral Res. 1992, 19(1), 55.

[20] Korba, B. E.; Gerin, J. L. Antiviral Res. 1995, $28(3), 225$.

(Li, L.; Lu, Z.) 